\title{
C- Reactive Protein Levels in Patients Diagnosed with Dengue Fever at a Tertiary Care Hospital, Mahabubnagar
}

\author{
Dr. Pallati Alekhya ${ }^{1}$, Dr. J. K. Surekha ${ }^{2 *}$, Dr. V. Rama Devi ${ }^{3}$, Mrs. Pragathi Yanam ${ }^{4}$ \\ ${ }^{1}$ Assistant Professor, ${ }^{2}$ Associate Professor, ${ }^{3}$ Professor \& HOD, Department of Microbiology, Government Medical College Mahabubnagar, Metugadda, \\ Mahabubnagar District, Telangana 509001, India \\ ${ }^{4}$ Tutor, Department of Microbiology, Government Medical College Mahabubnagar, Metugadda, Mahabubnagar District, Telangana 509001, India
}

DOI: $\underline{10.36348 / \mathrm{sjpm} .2020 . \mathrm{v} 05 \mathrm{i} 01.008}$

| Received: 21.01.2020 | Accepted: 28.01.2020 | Published: 30.01 .2020

*Corresponding author: Dr. J. K. Surekha

\section{Abstract}

Dengue, an arboviral infection is a notifiable disease in India and is endemic in many regions of the country. CRP levels help in knowing the severity of the disease. Patients with signs and symptoms of Dengue were included in the study. Their demographic data was noted. Serum was tested for NS1 ELISA, IgM ELISA. Positive samples were tested for CRP levels. Platelet count and Blood transfusion data was noted. Dengue positivity was $21 \%$, with male predominance (55.6\%), common in young children and teens. CRP level of $12 \mathrm{mg} / \mathrm{L}$ was seen in $28.40 \%$ of patients. Patients with CRP of $48 \mathrm{mg} / \mathrm{L}$ required multiple platelet transfusion. Our study has correlated dengue positive patient's platelets, CRP levels and need for blood transfusion.

Keywords: Dengue, CRP, blood transfusion, Mahabubnagar, NS1 ELISA, IgM ELISA.

Copyright @ 2020: This is an open-access article distributed under the terms of the Creative Commons Attribution license which permits unrestricted use, distribution, and reproduction in any medium for non-commercial use (NonCommercial, or CC-BY-NC) provided the original author and sources are credited.

\section{INTRODUCTION}

Dengue virus is endemic in many countries of the world. In India, it is the commonest Arboviral disease [1-2]. The vector transmitting the infection is Aedes agypti, and Aedes albpictus. The clinical classification given by WHO in 2009 is followed worldwide. The stages are divided based on severity of the infection into i-Dengue with or without warning signs, ii-Severe Dengue [1]. However clinical presentation varies with age and secondary infection [2]. It varies from simple self limiting disease to severe dengue shock. In India, it is endemic in all the states. In Mahabubnagar district of Telangana seroprevalence during the year 2017 was $7 \%$ [3].

$\mathrm{C}$ - reactive protein (CRP) is commonly used biomarker in the prognosis of infective diseases \& inflammatory conditions [4]. In early period of Dengue infection, CRP helps in differentiating DF from severe DF. C - reactive protein is a biomarker which can be easily detected by simple latex agglutination test.

This study was conducted to compare the platelets values and CRP levels in dengue positive patients and assess the severity and prognosis of disease.

\section{MATERIAL \& METHODS}

The prospective study was conducted at a tertiary care hospital at Mahabubnagar over a period of 3 months (July-Sep-2019). Blood samples were collected from 2768 patients based on clinical signs \& symptoms of dengue.

\section{Patient Inclusion and Exclusion Criteria}

Patients suffering from 2-20 days fever with or without rash, decreased platelets, retro orbital pain, arthralgia, head ache, myalgia, and malaise were included in the study. Patients of Immune compromised status were excluded.

\section{Sample Collection \& Processing}

2-3 ml of blood was collected under aseptic conditions according to standard sample collection protocol. Serum was separated and laboratory tests were performed.

Serum samples collected from patients suffering from fever of less than 5 days were subjected to antigen detection. Pan bio dengue ELISA kit was used (dengue NS1 capture ELISA). Serum samples of patients suffering from fever of more than 5 days were subjected to dengue IgM antibody detection. NIV dengue IgM capture ELISA kit (sandwich ELISA) was used. Tests were done according to the manufacturer 
guidelines. Results were recorded based on OD values of the sample.

For positive dengue cases, CPR latex agglutination test was done using arkray kit. If test was positive, the result was reported in dilutions. Based on the platelets levels and patients clinical condition, platelet transfusion (SDP \& RDP) was done according to the institution protocols. Platelet count, blood transfusion and recovery data was collected from the blood bank, patient record and medical record section.

\section{RESULT}

A total of 2768 samples were tested for dengue infection during 3 months (July-Sep-2019), out of which $595(21 \%)$ samples were positive for dengue infection. Among them NS1 ELISA positives were 137 cases $(23.02 \%)$ and 458 cases $(76.9 \%)$ were positive for IgM ELISA (Chart-1). Out of 595 patients, males were predominant $(55.6 \%)$ (Chart-2). The positive cases were seen in majority of children below 10 years (35.46\%) and adolescent group (29.07\%) (Chart-3).

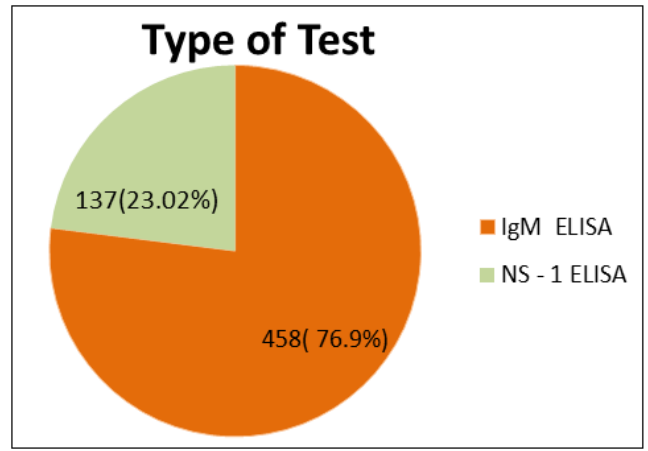

Chart-1: Tests done for dengue

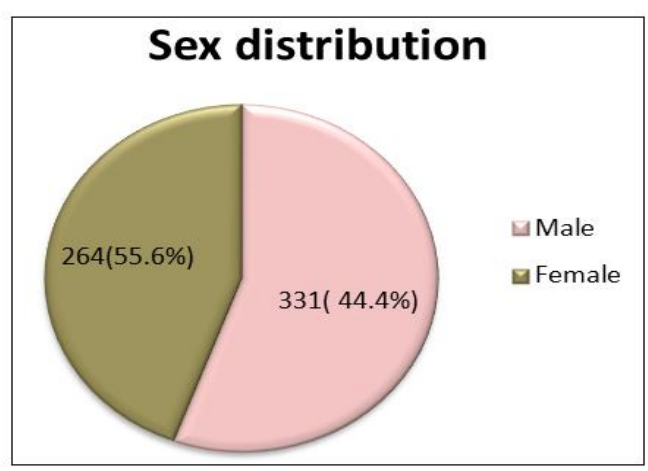

Chart-2: Sex Distribution

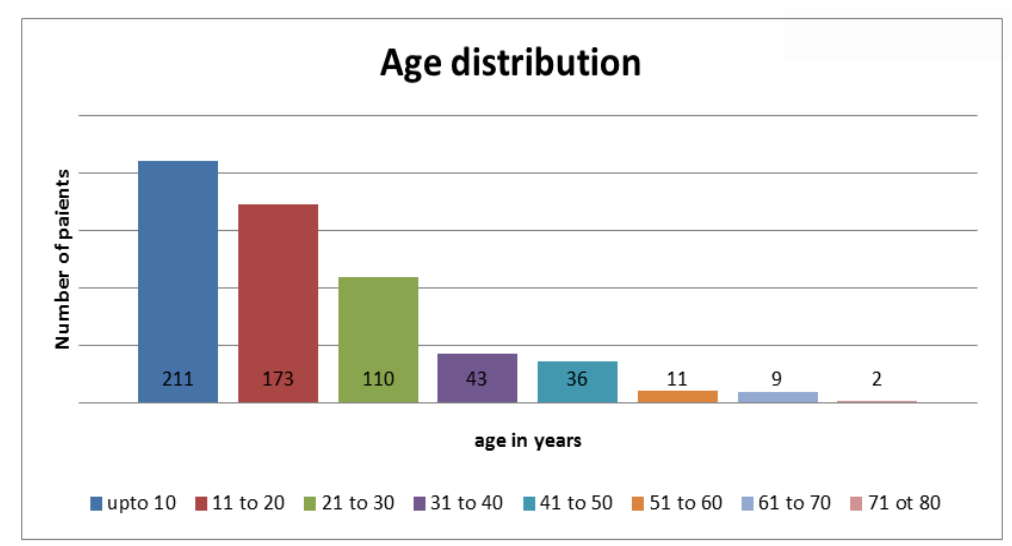

Chart-3: Age Distribution

Among 595 positive dengue cases, 362 were negative for CRP and 233 cases showed positive CRP, out of which 1 in 2 dilutions (12) were seen majority of the cases (Chart-4).

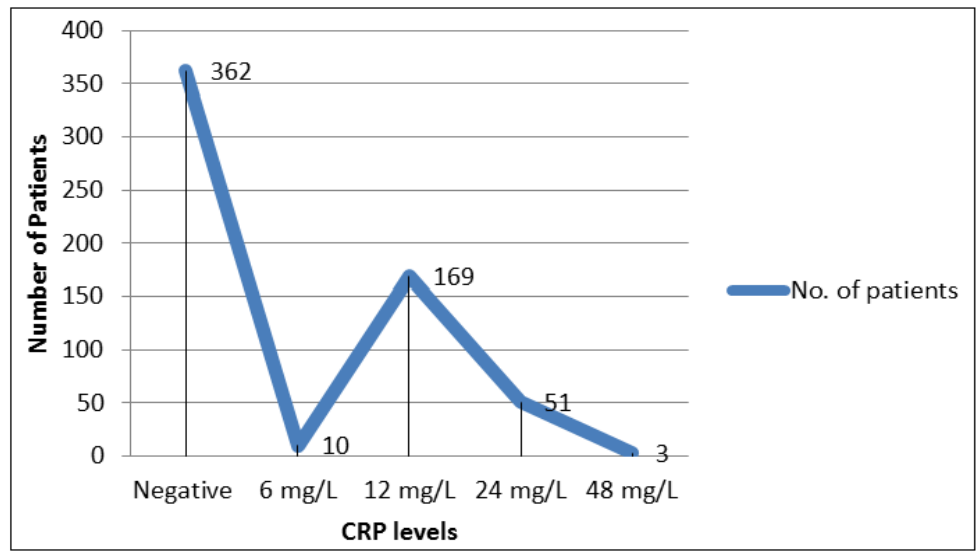

Chart-4: CRP levels 
Up to $10,000 / \mu \mathrm{L}$ platelet level was seen in $3.36 \%$ of the patients. $11,000-50,000 / \mu \mathrm{L}$ was seen in $29.91 \%$ patients. 51,000 to $1,00,000 / \mu \mathrm{L}$ was seen $14.95 \%$ patients, $51.76 \%$ have more than $1,00,000 / \mu \mathrm{L}$. For 198 patients, platelet transfusion was done. Single Donor Platelet (SDP) was transfused for 20 patients (Table-1), among these, 2 patients had CRP level 1 in 8 dilution $(48 \mathrm{mg} / \mathrm{L}), 4$ patients had 1 in 4 dilution $(24$ $\mathrm{mg} / \mathrm{L}), 12$ patients had 1 in 2 dilution (12 mg/L), 2 patients had negative CRP. Random Donor Platelets (RDP) was transfused for 178 patients (Table-2), among these, 1 patient had CRP level 1 in 8 dilution (48 $\mathrm{mg} / \mathrm{L}), 34$ patients had 1 in 4 dilution $(24 \mathrm{mg} / \mathrm{L}), 124$ patients had 1 in 2 dilution $(12 \mathrm{mg} / \mathrm{L}), 7$ patients had 1 in 1 dilution $(6 \mathrm{mg} / \mathrm{L})$ and 12 patients had negative CRP. Remaining 397 patients had no transfusions (Table-3), among them 5 patients had CRP levels 1 in 4 dilution $(24 \mathrm{mg} / \mathrm{L}), 41$ patients had 1 in 2 dilution (12 $\mathrm{mg} / \mathrm{L}), 3$ patients had CRP 1 in 1 dilution $(6 \mathrm{mg} / \mathrm{L})$ and 348 patients had negative CRP. There was zero mortality seen in patients due to dengue infection.

Table-1: CRP levels of patients in whom platelet count was less than $20,000 / \mu \mathrm{L}$

\begin{tabular}{|l|l|}
\hline CRP level & Number of patients \\
\hline Negative & 2 \\
\hline $6 \mathrm{mg} / \mathrm{L}$ & 0 \\
\hline $12 \mathrm{mg} / \mathrm{L}$ & 4 \\
\hline $24 \mathrm{mg} / \mathrm{L}$ & 12 \\
\hline $48 \mathrm{mg} / \mathrm{L}$ & 2 \\
\hline
\end{tabular}

Table-2: CRP levels of patients from whom platelet count was $20,000-50,000 / \mu \mathrm{L}$

\begin{tabular}{|l|l|}
\hline CRP level & Number of patients \\
\hline
\end{tabular}

\begin{tabular}{|l|l|}
\hline Negative & 12 \\
\hline $6 \mathrm{mg} / \mathrm{L}$ & 7 \\
\hline $12 \mathrm{mg} / \mathrm{L}$ & 124 \\
\hline $24 \mathrm{mg} / \mathrm{L}$ & 34 \\
\hline $48 \mathrm{mg} / \mathrm{L}$ & 1 \\
\hline
\end{tabular}

Table-3: CRP levels of patients from whom platelet count was $50,000 / \mu \mathrm{L}$ and above

\begin{tabular}{|l|l|}
\hline CRP level & Number of patients \\
\hline Negative & 348 \\
\hline $6 \mathrm{mg} / \mathrm{L}$ & 3 \\
\hline $12 \mathrm{mg} / \mathrm{L}$ & 41 \\
\hline $24 \mathrm{mg} / \mathrm{L}$ & 5 \\
\hline $48 \mathrm{mg} / \mathrm{L}$ & 0 \\
\hline
\end{tabular}

\section{DISCUSSION}

Dengue fever is a major global public health problem, especially in the tropical and subtropical countries. The burden of the disease is particularly seen in countries like India, where, during the dengue "season," the health care system is overwhelmed by patients with dengue fever [5]. The dengue disease is widely distributed in almost 35 states/UTs in India [6, 7]. In India, dengue is a notifiable disease. The seroprevalence of dengue in Mahabubnagar district in the year 2017 was $7 \%$ and maximum numbers of cases were seen during the month of September [3]. This study was conducted at the same center and time period was taken as 3 months around the peak season.

The positivity during of the study was $21 \%$. The positives were detected more by IgM ELISA test as majority of the patients presented after 5 days of duration of fever. $35.46 \%$ of the cases were seen in children less than 10 years of age. Shubhankar Mishra et al., [8] conducted study on children up to 14 years of age. This correlated with the study of Udayasri et al., [3], Chakravarthi et al., [9], Gupta et al., [10], Pandya et al., [11]. Male predominance $(55.65 \%)$ was seen in the present study and this correlates with majority of studies [2-10].

CRP levels are of significant importance in prognosis of many diseases. In this study, patients having CRP levels of $48 \mathrm{mg} / \mathrm{L}$ and $24 \mathrm{mg} / \mathrm{L}$, all required platelet transfusion either SDP or RDP. These patients also were transfused multiple times. Whereas patients with CRP $12 \mathrm{mg} / \mathrm{L}$ rarely required platelet transfusion (RDP). And patients with negative CRP recovered well and didn't require any transfusion. The transfusion of SDP or RDP was decided on platelet count of the patient. Chien-Chih Chen et al., [12] conducted a study to determine the utility of CRP in different stages of Dengue infection and concluded "single measurement of CRP as a potential useful and simple biomarker to identify patients who are at risk for developing a more severe dengue illness and to help triage patients requiring hospital care."

In conclusion, CRP as a biomarker helps clinician in estimating the patient condition, severity of the disease and guides them for further plan of treatment for the patient and decrease their hospital stay. Especially, this is important at a government setup where resources are limited.

\section{ACKNOWLEDGMENTS}

I would acknowledge Dr. Srilatha for providing the information related to blood bank. I would like to thank Mrs. Roja Rani, Mr. Veeranjaneyulu, Mr. Kishore, Mr. Venkatesh and Mr. Shiva for performing the tests.

\section{REFERENCES}

1. Apurba, S. S., \& Sandhya, B. Essential of Medical Microbiology. $2^{\text {nd }}$ Edition. Jaypee. 502-511.

2. Pan, S. T., Su, P. A., Chen, K. T., Lin, H. J., \& Lai, W. P. (2014). Comparison of the clinical manifestations exhibited by dengue and nondengue patients among children in a medical center in southern Taiwan. Journal of Acute Medicine, 4(2), 53-56.

3. Udayasri, B., Ramadevi, V., Surekha, J. K., \& Alekhya, P. (2019). Saudi journal of Pathology \& Microbiology. 49(3); 264-267. 
4. Nguyen, T. T. P., Bui, T. L., Nguyen, T. H., \& Tran, D. T. (2019). C-reactive protein in children with dengue fever in Vietnam. International Journal of Research in Pharmaceutical Sciences, 10(3), 2525-2531.

5. John, K. J., Gunasekaran, K., Prasad, J. D., Mathew, D., Das, S., Sultan, N., ... \& Iyyadurai, R. (2019). Predictors of Major Bleeding and Mortality in Dengue Infection: A Retrospective Observational Study in a Tertiary Care Centre in South India. Interdisciplinary perspectives on infectious diseases, 2019.

6. Gupta, N., Srivastava, S., Jain, A., \& Chaturvedi, U. (2012). Dengue in India. The Indian journal of medical research, 136(3), 373-390.

7. India, Ministry of Health and Family Welfare. National Vector Borne Disease Control Programme. New Delhi: Directorate General of Health Services; 2016. Available from: http://www.nvbdcp.gov.in. [Last accessed on 2016 Jan 08].

8. Mishra, S., Ramanathan, R., \& Agarwalla, S. K. (2016). Clinical profile of dengue fever in children: a study from Southern Odisha, India. Scientifica, 2016.

9. Chakravarti, A., \& Kumaria, R. (2005). Ecoepidemiological analysis of dengue infection during an outbreak of dengue fever, India. Virology Journal, 2(1), 32.

10. Gupta, E., Dar, L., Kapoor, G., \& Broor, S. (2006). The changing epidemiology of dengue in Delhi, India. Virology journal, 3(1), 92.

11. Pandya, G. (1982). Prevalence of dengue infection in India. Defence Science Journal, 32(4), 359-370.

12. Chen, C. C., Lee, I. K., Liu, J. W., Huang, S. Y., \& Wang, L. (2015). Utility of C-reactive protein levels for early prediction of dengue severity in adults. BioMed research international, 2015. 